\title{
Sistem Informasi Penerimaan Pendeta pada Kantor Pusat GKPS Berbasis Web
}

\author{
Chika Meyana Saragih ${ }^{1}$, Romanus Damanik ${ }^{2}$ \\ 1,2 Universitas Katolik Santo Thomas, Jln. Setia Budi No.479-F Medan, 061-8210161, Indonesia
}

\begin{tabular}{lll}
\hline ARTICLE INFORMATION & A B S T R A K \\
\cline { 1 - 2 } $\begin{array}{l}\text { Received: March 3,2019 } \\
\text { Revised: March 19,2019 } \\
\text { Available online: April 08,2019 }\end{array}$ & $\begin{array}{l}\text { Sistem yang dibangun adalah sebuah sistem yang membahas sistem informasi } \\
\text { peneriman pendeta pada kantor pusat GKPS menggunakan Bahasa } \\
\text { Pemrograman JAVA, PHP dan Database menggunakan MySQL, dimana dengan } \\
\text { KeYstem yang sudah dibangun, pihak Personalia akan lebih mudah dan cepat dalam } \\
\text { memproses Penerimaan pendeta ,Sistem yang dibangun akan membantu } \\
\text { personalia kantor pusat GKPS dalam menangani pendaftaran calon pendeta dan } \\
\text { pencetakan laporan pendeta. }\end{array}$ \\
$\begin{array}{ll}\text { Pendeta, GKPS, MySQL, Sistem Informasi } \\
\text { Phone: +6282272979119 }\end{array}$ & \\
\hline E-mail: c_meyana@yahoo.com
\end{tabular}

\section{PENDAHULUAN}

Pesatnya perkembangan teknologi dan komputersasi pada saat ini dapat dimanfaatkan dalam meningkatkan efektifitas dan efisien sikinerja dari kepegawaian. Oleh Karena itu, keahlian dalam menguasai teknologi dan informasi dibutuhkan sumber daya manusia yang memiliki ilmu pengetahuan serta kemampuan yang memadai[1].

Kantor pusat GKPS tidak terlepas dari yang namanya permasalahan, dengan adanya penerimaan pendeta yang dilakukan oleh kantor tersebut masih berjalan dengan manual. Berdasarkan survei pendahuluan yang dilakukan, para calon pendeta mendaftar dengan mengisi formulir pendaftaran yang telah disediakan oleh Kantor pusat bagian biro personalia. Beberapa syarat yang ditentukan kantor pusat dalam proses penerimaan pendeta untuk mengadakan seleksi dan ujian dengan syarat : indeks prestasi kumulatif (IPK) 2,50 umur maksimal 35 tahun pada saat mendaftar. Surat pernyataan tunduk kepada aturan dan peraturan GKPS. Surat pernyataan bersedia ditempatkan diseluruh wilayah pelayanan GKPS (di atas kertas bermaterai)[2].

Bagi mereka yang memenuhi syarat tersebut diminta datang ke biro personalia GKPS untuk mengisi formulir pendaftaran dengan membawa surat permohonan yang ditulis sendiri diatas kertas segel dan bermaterai. Dengan melampirkan data data pribadi, ijazah SD,SMP,SMA,S1, pas photo dan surat keterangan berkelakuan baik dari lembaga pendidikan teologi yang bersangkutan[3].

Yang telah memenuhi syarat diundang mengikuti tes penerimaan calon pelayanan (ujian tulisan dan lisan/wawancara). Adapun materi ujian: Pengetahuan isi Alkitab, pengenalan tentang GKPS (dogma,aturan dan peraturan dan perangkat-perangkat GKPS), sejarah gereja umum GKPS , Psikologi ( motivasi, spritualitas ). Selanjutnya calon pendeta menunggu jadwal seleksi yang akan diumumkan dengan cara menempel jadwal seleksi di papan pengumuman. Lalu para calon pendeta melihat jadwal seleksi masing-masing di papan pengumuman dan melaksanakan seleksi tersebut. Dan hasil seleksi para calon pendeta akan diumumkan kembali di papan pengumuman untuk menginformasikan calon pendeta dinyatakan lulus atau tidak lulus, setelah calon pendeta dinyatakan lulus di tahap seleksi awal maka calon pendeta akan diberi tempat pelayanan (Gereja) yang ditentukan oleh kantor pusat. Pada saat penempatan, para calon pendeta akan diberi masa pelayanan selama 2 (dua) tahun untuk melihat kinerja calon pendeta dengan mengevaluasi laporan yang dibuat oleh masing-masing calon pendeta yang dikirim ke kantor pusat seminggu sekali, adapun laporan tersebut akan memudahkan kantor pusat memilih calon pendeta yang akan dinyatakan lulus atau tidak lulus yang menjadi tahap akhir seleksi pengangkatan pendeta. Berdasarkan hasil evaluasi yang dilakukan selama dua tahun maka calon pendeta akan dinyatakan lulus atau tidak lulus, calon pendeta yang dinyatakan lulus akan ditabalkan menjadi pendeta sedangkan bagi calon pendeta yang tidak lulus akan ditabalkan menjadi vikar.

Berdasarkan hasil pengamatan peneliti lakukan pada kantor pusat GKPS Pematangsiantar didapat masalah mengenai proses data penerimaan pendeta masih dilakukan dengan manual ini dapat menyebabkan kesulitan dalam pencarian maupun penerimaan pendeta. Oleh sebab itu perlunya dibuat sebuah pengembangan sistem untuk proses pengolahan data agar lebih cepat dalam proses pencarian data penerimaan pendeta[4]. 
Hal ini menyebabkan peneliti tertarik untuk membangun sebuah sistem informasi tentang penerimaan pendeta yang berbasis web, yang berguna untuk mempercepat pekerjaan mereka dalam penyimpanan dan pencarian penerimaan pendeta. Berdasarkan uraian diatas peneliti tertarik untuk meneliti dengan mengambil judul "Sistem Informasi Penerimaan Pendeta Pada Kantor Pusat GKPS “, yang bertujuan untuk mempermudah dan mempercepat proses penyampaian informasi tentang penerimaan pendeta pada kantor pusat GKPS.

\section{METODOLOGI PENELITIAN}

Adapun metodologi penelitian pada penelitian[5] ini adalah :

1. Observasi

Teknik pengumpulan data melalui pangamatan yang dilakukan terhadap objek yang akan di teliti dengan menggunakan pencatatan secara sistematis terhadap informasi pelaksanaan calon pendeta pada kantor pusat GKPS.

2. Interview/Wawasan

Metode pengumpulan data yang dilakukan dengan cara Tanya jawab secara langsung kepada pemilik tempat pada kantor pusat GKPS.

3. Studi Pustaka

Studi pustaka yaitu penelitian yang dilakukan dengan cara membaca dan mempelajari buku-buku yang berhubungan dengan masalah yang akan di teliti sebagai tinjauan pustaka. Dalam penelitian ini, referensi yang dugunakan berupa buku serta penelusuran melalui internet

\subsection{Konsep Dasar Sistem}

\section{LANDASAN TEORI}

Sistem merupakan suatu jaringan kerja dari prosedur-prosedur yang saling berhubungan, berkumpul dan bersama-sama untuk melakukan suatu kegiatan atau untuk menyelesaikan suatu sasaran tertentu. Suatu sistem terdiri dari sejumlah komponen yang saling berinteraksi, saling bekerja sama membentuk satu kesatuan. Komponen-komponen sistem atau elemen-elemen sistem dapat berupa suatu sub sistem atau bagian-bagian dari sistem[6].

Setiap sub sistem mempunyai sifat-sifat dari sistem untuk menjalankan suatu fungsi tertentu dan mempengaruhi proses sistem secara keseluruhan. Media penghubung antara satu sub sistem dengan sub sistem yang lainnya biasa disebut deng penghubung (interface). Melalui penghubung ini memungkinkan sumber-sumber daya mengalir dari satu sub sistem ke sub sistem yang lainnya. Melalui penghubung keluaran (output) untuk sub sistem akan menjadi masukan (input) sub sistem yang lainnya.

Dengan penghubung satu sub sistem dapat berinteraksi dengan sub sistem yang lainnya membentuk satu kesatuan. Suatu sistem pasti mempunyai satu tujuan (goal) atau sasaran (objective). Sasaran dari sistem sangat menentukan masukan yang dibutuhkan sistem dan keluaran yang akan dihasilkan sistem[6], [7]

\subsection{Konsep Dasar Sistem Informasi}

Informasi adalah data yang diolah menjadi bentuk yang lebih berguna dan lebih berarti bagi penerimanya. Sumber informasi adalah data. Data kenyataannya yang menggambarkan suatu kejadian-kejadian dan kesatuan nyata. Kejadian-kejadian (event) adalah kejadian yang terjadi pada saat tertentu). Informasi merupakan : "Data yang telah diolah menjadi sebuah bentuk yang berarti bagi penerimanya dan bermanfaat bagi pengambilan keputusan saat ini atau saat mendatang”[4], [8]

Sistem informasi merupakan suatu sistem dalam suatu organisasi yang mempertemukan kebutuhan pengolahan transaksi harian yang mendukung fungsi operasi organisasi yang bersifat manajerial dengan kegiatan strategi dari suatu organisasi untuk dapat menyediakan kepada pihak luar tertentu dengan informasi yang diperlukan untuk pengambilan keputusan [9]

\section{HASIL DAN PEMBAHASAN}

\subsection{Analisa sistem}

Bagian arsip/kepustakaan merupakan bagian yang berperan sebagai administrasi di kantor pusat GKPS yang mengolah arsiparsip dan laporan data pendeta yang ada di pusat GKPS. Selama ini pengolahan data pendeta di pusat GKPS masih dilakukan dengan cara data yang masuk dicatat pada lembaran kertas dan diarsipkan saja dalam sebuah buku lalu ditaruh dalam sebuah rak penyimpanan (secara manual). Sehingga dirasakan pengolahan data pendeta pada sistem yang sedang berjalan kurang optimal[3]. Beberapa kendala yang dihadapi pihak pusat GKPS itu, mereka mengeluhkan beberapa masalah yang timbul, antara lain :

1. Pembuatan laporan dan pendaftaran calon pendeta yang memakan waktu yang lama dan melelahkan

2. Arsip-arsip yang lama menumpuk sehingga membuat media penyimpanan penuh dan kurang tertata rapi.

3. Lambatnya proses pencarian data data lama yang sewaktu waktu diperlukan. 
Hal ini disebabkan karena banyaknya arsip yang harus diolah dengan cara yang masih belum terstruktur dan terkadang didukung dengan system penyimpanan arsip fisik yang kurang tertata rapi. Penyimpanan arsip yang kurang tertata dan tidak adanya label tahun serta pengurutan berdasarkan abjad yang memisahkan setiap arsip inilah yang juga menjadi hambatan bagi admin yang akan menerapkan pengarsipan secara terpusat.

Untuk mengatasi masalah kelemahan yang telah diuraikan di atas, berikut ini akan dibuat analisa kebutuhan yang diperlukan kantor pusat GKPS:

1. Dengan sistem ini terkomputerisasi, laporan-laporan yang telah dibuat dapat tersimpan rapi dan tidak akan rusak. Serta apabila sewaktu-waktu pimpinan pusat ingin melihat laporan-laporan yang lampau, maka dapat dilihat jelas dengan cepat.

2. Dengan sistem yang akan dibuat ini, proses pencarian data pendeta akan lebih cepat dan tepat.

3. Dari sistem yang dibuat ini dengan memanfaatkan teknologi komputer, yaitu berbasis web sehingga banyak menawarkan kemudahan bagi pemakai dan juga kantor pusat GKPS maupun masyarakat

\subsection{Perancangan Sistem}

Setelah melakukan analisa sistem yang berjalan selanjutnya melakukan proses perancangan sistem. Perancangan sistem akan dimulai setelah tahap analisis terhadap sistem yang sedang berjalan selesai dilakukan, perancangan sistem dapat didefinisikan sebagai penggambaran, perencanaan dan pembuatan sketsa atau pengaturan dari beberapa elemen yang terpisah ke dalam satu kesatuan yang utuh dan berfungsi. Langkah pertama yang dilakukan dalam perancangan sistem adalah menggambarkan sistem secara umum yang akan dibangun.

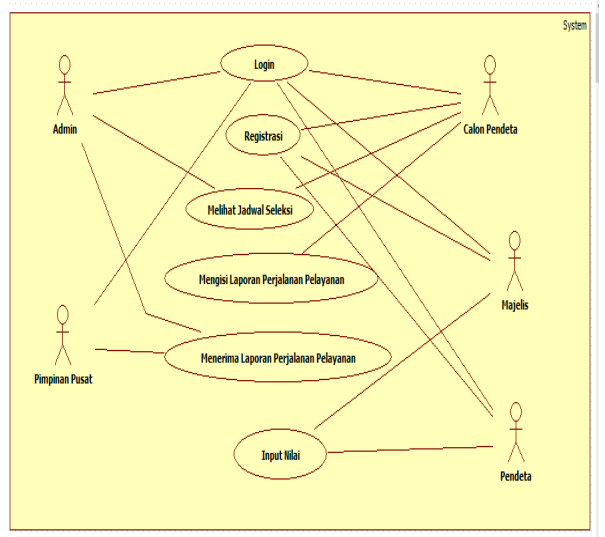

Gambar 1. Use Case Diagram

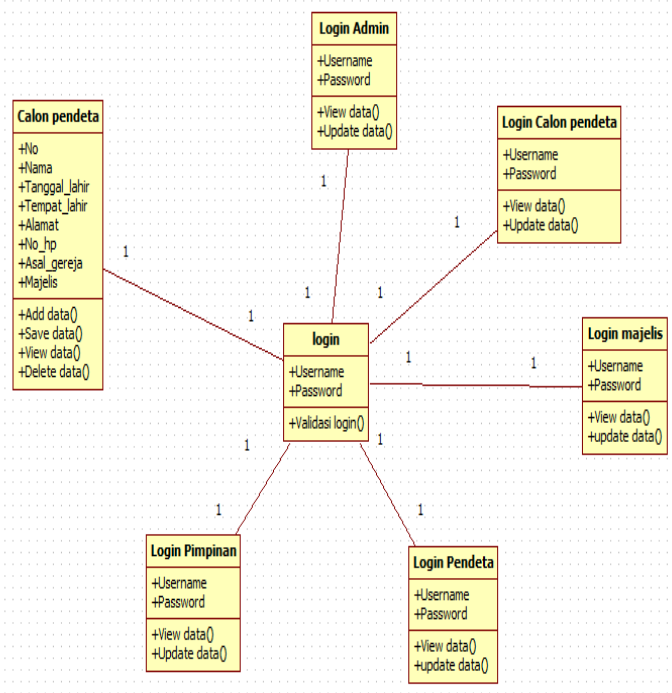

Gambar 2. Class Diagram 


\subsection{Implementasi}

Implemetansi sistem merupakan suatu tindakan atau pelaksanaan rencana yang telah disusun cermat dan rinci (matang) dengan prosedur atau tahap penerapana sistem yang dilakukan untuk menyelesaikan rancangan desain yang telah disetujui program yang telah dibuat pada tahap perancangan sistem agar siap untuk dioperasikan.

Implementasi interface (antarmuka) merupakan tahapan atau langkah-langkah untuk memenuhi kebutuhan user dalam berinteraksi dengan computer. Adapun interface pada sistem yang akan dibangun terdapat beberapa tampilan halaman. Pada setiap tampilan halaman dijelaskan sebagai berikut :

Halaman beranda merupakan tampilan awal dari sistem ini yang menyediakan fitur-fitur apa saja yang tersedia. Tampilan halaman beranda dapat dilihat pada gambar 3 berikut:

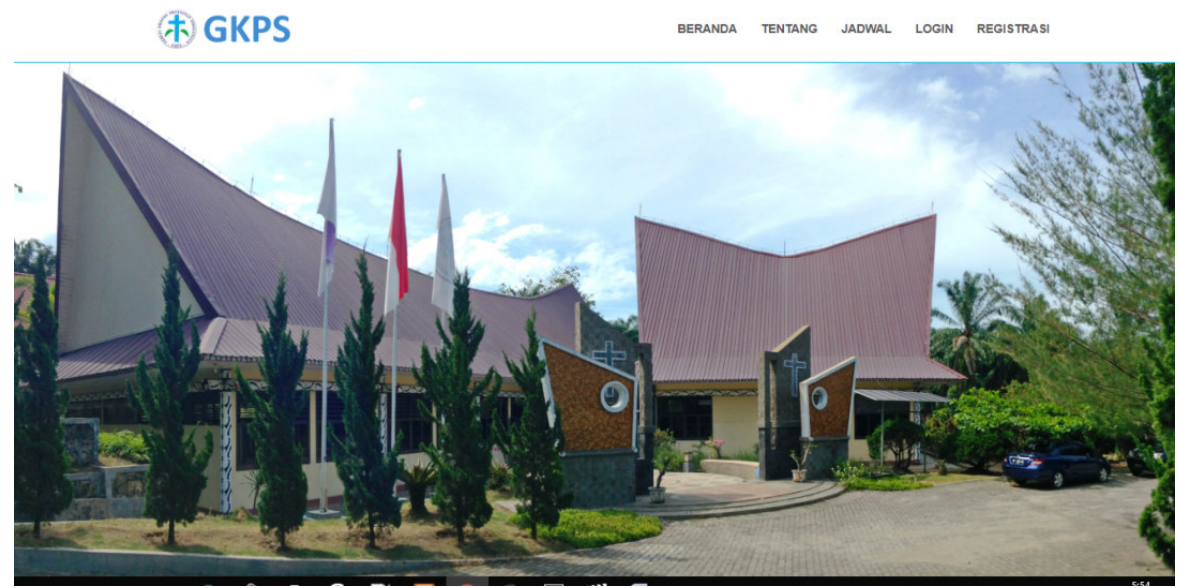

Gambar 3: Halaman Beranda

Halaman tentang ini digunakan untuk melihat informasi tentang kantor pusat GKPS. Tampilan halaman tentang dapat dilihat pada gambar 4 berikut.

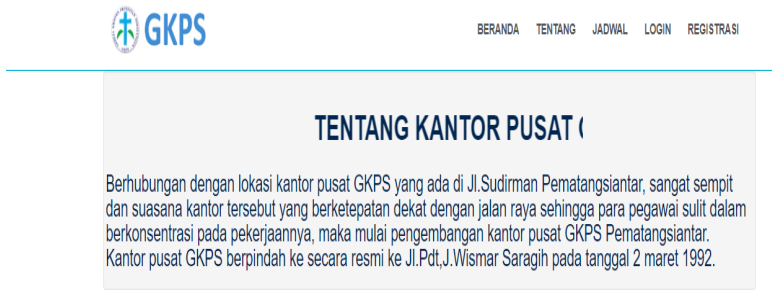

Gambar 4 : Tampilan Halaman Profil

Halaman jadwal ini digunakan untuk melihat jadwal pekerjaan yang ada dikantor pusat GKPS. Tampilan halaman jadwal dapat dilihat pada gambar 5:

(木) GKPS Beranda tentang jadwal Login registrasi

\section{JADWAL HARI KERJA}

Senin - Kamis $=$ Pukul $08.00 \mathrm{~s} / \mathrm{d} 15.00$ wib

Jumat $=$ Pukul $08-00 \mathrm{~s} / \mathrm{d} 12.00 \mathrm{wib}$

Sabtu - Minggu $=$ TUTUP

Gambar 5 : Tampilan Jadwal Hari Kerja

Menu ini terdiri dari form login ke dalam sistem yang dapat digunakan untuk semua user. Tampilan menu login dapat dilihat pada gambar 6. 


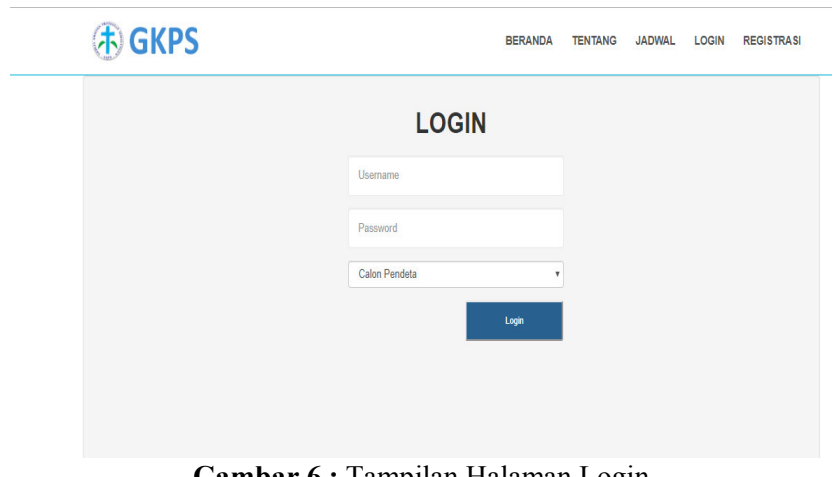

Gambar 6 : Tampilan Halaman Login

\section{KESIMPULAN}

Berdasarkan pada hasil pengumpulan data yang telah didapatkan ataupun diperoleh, maka didapatlah beberapa kesimpulan dari Sistem informasi penerimaan pendeta pada kantor pusat GKPS berbasis web yang akan dibangun untuk memenuhi kebutuhan pengguna, yaitu :

1. Dengan adanya sistem ini dapat memanfaatkan untuk mengolah data penerimaan pendeta secara baik karena sistem yang dirancang lebih efektif bagi kepegawaian di kantor pusat GKPS.

2. Dengan adanya mempercepat informasi penerimaan pendeta GKPS.

3. Dengan adanya meningkatkan bagian personalia dalam mengajukan laporan kepada pimpinan pusat.

\section{DAFTAR PUSTAKA}

[1] H. M. Jogiyanto, Analisis dan Desain (Sistem Informasi Pendekatan Terstruktur Teori dan Praktek Aplikasi Bisnis). Yogyakarta: Penerbit Andi, 2017.

[2] GKPS, "GKPS - GEREJA KRISTEN PROTESTAN SIMALUNGUN," Web Gereja GKPS Indonesia, 2019. [Online]. Available: http://gkps.or.id/. [Accessed: 29-Jan-2020].

[3] P. Pusat, G. Kristen, and P. Simalungun, "Peraturan Mutasi Pendeta," pp. 1-4, 2012.

[4] T. Sutabri, Analisa Sistem Informasi. Yogyakarta: Andi, 2012.

[5] Sugiyono, Metode Penelitian Kuantitatif, Kualitatif dan R\&D. Bandung: PT Alfabet, 2016.

[6] T. Sutabri, Konsep Sistem Informasi. Penerbit Andi, 2012.

[7] T. Limbong, "Sistem Informasi Kehadiran Dosen Dan Jadwal Pengganti Perkuliahan Berbasis Short Message Service (SMS)," Inf. Dan Teknol. Ilm. Budi Darma, LPPM STMIK Budi Darma, 2014.

[8] A. Kadir, Pengenalan sistem informasi. Andi, 2003.

[9] M. W. Santoso and B. Hariadi, "Rancang Bangun Sistem Informasi Potensi Pertanian Tanaman Pangan Di Kabupaten Jombang (Studi Kasus: Kecamatan Megaluh) | Santoso | Jurnal JSIKA," JSIKA, 2012. [Online]. Available: https://jurnal.dinamika.ac.id/index.php/jsika/article/view/105. [Accessed: 06-Dec2019]. 